\title{
Pneumatocele, Pneumocephalus or Aerocele
}

\author{
Pneumatocele, Pneumocefalo ou Aerocele
}

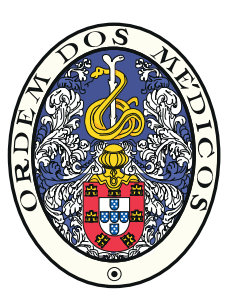

Jana ZELINOVÁ $\triangle^{1}$, Marta CUSTÓDIO ${ }^{1}$, Anabela Salgueiro MARQUES ${ }^{1}$ Acta Med Port 2018 Jan;31(1):67-67 - https://doi.org/10.20344/amp.9666

Keywords: Hematoma, Subdural; Pneumocephalus; Skull Fractures; Trephining

Palavras-chave: Fracturas Cranianas; Hematoma Subdural Pneumocefalia; Trepanação

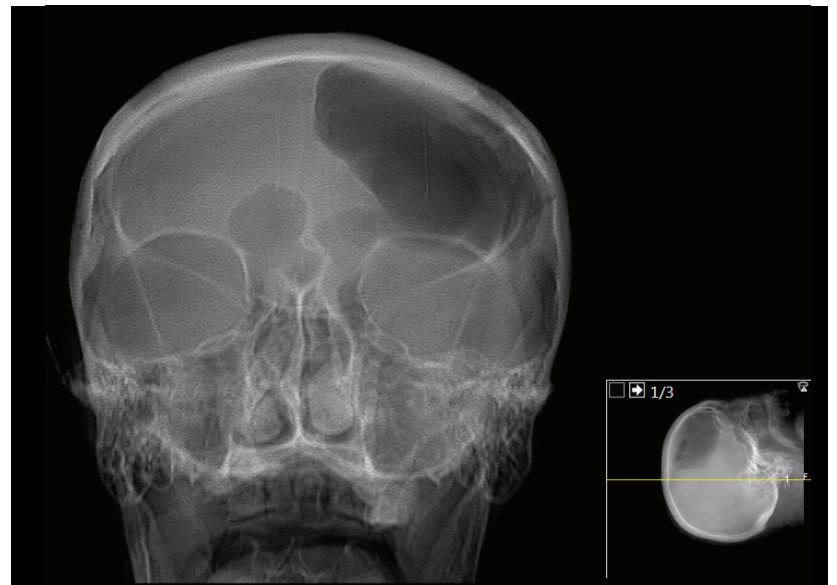

Figure 1 - Radiography image of the computerized tomography with the hyper transparence on the left side of frontal image

An 85 year-old man with head trauma, complicated by bilateral fronto-temporal subdural hematoma was subjected to drainage by trepanation, without neurological sequelae.

One month later, he was re-admitted in the emergency department with gradual deterioration of his neurological state. Clinically, he had a Glasgow coma scale of 9 points (E2M5V2). Head tomography revealed a large left frontal epidural pneumatocele with $45 \mathrm{~mm}$ of maximum thickness causing mass effect (midline deviation of $6 \mathrm{~mm}$ ), and in particular, deforming and collapsing the left lateral ventricle (Fig.s 1 and 2).

A dehiscence of the frontal surgical wound was

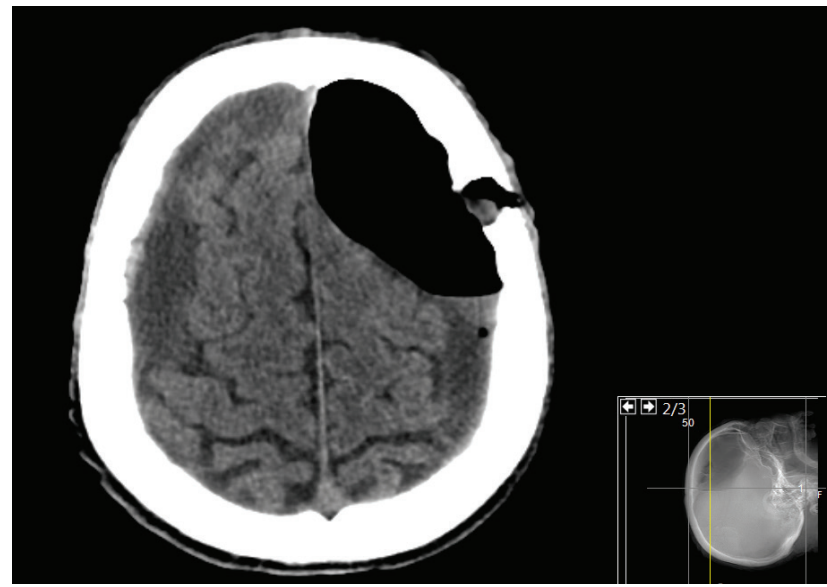

Figure 2 - The computed tomography image show the air with its very low density, compressing, deforming and collapsing the left lateral ventricle, showing the dehiscence of frontal surgical wound

confirmed, leading to neurosurgical debridement and closure. A positive recovery was observed.

The presence of gas or air in any intracranial compartment it is called pneumatocele, pneumocephalus or aerocele; it can be extra-axial (epidural, subdural, subarachnoid) or intra-axial (parenchymal, intra-ventricular, intra-vascular). ${ }^{1-3}$

It is most commonly encountered following trauma or surgery and is rarely associated with infections and tumors. ${ }^{1-3}$

It can be fatal if not treated properly. ${ }^{1-3}$

\section{ACKNOWLEDGEMENTS}

Authors are thankful to neurosurgeon team of São Francisco Xavier Hospital PROTECTION OF HUMANS AND ANIMALS

The authors declare that the procedures were followed according to the regulations established by the Clinical Research and Ethics Committee and to the Helsinki Declaration of the World Medical Association.

\section{DATA CONFIDENTIALITY}

The authors declare having followed the protocols in use at their working center regarding patients' data publication. Informed consent was duly obtained from the patient.

\section{CONFLICTS OF INTEREST}

All authors report no conflict of interest.

\section{FUNDING SOURCES}

This research received no specific grant from any funding agency in the public, commercial, or not-for-profit sectors.

\section{REFERENCES}

1. Schirmer CM, Heilman CB, Bhardwaj A. Pneumocephalus: case illustrations and review. Neurocrit Care. 2010;13:152-8.

2. Dabdoub CB, Salas G, Silveira EN, Dabdoub CF. Review of the management of pneumocephalus. Surg Neurol Int. 2015;6:155.

3. Kankane VK, Jaiswal G, Gupta TK. Posttraumatic delayed tension pneumocephalus: Rare case with review of literature. Asian J Neurosurg. 2016;11:343-7.

1. Internal Medicine Department. Hospital de Cascais. Cascais. Portugal.

$\triangle$ Autor correspondente: Jana Zelinová. janka.zelinova@yahoo.com

Recebido: 11 de setembro de 2017 - Aceite: 22 de novembro de 2017| Copyright $\odot$ Ordem dos Médicos 2018 